\title{
Contractual arrangements: NHS use of the private sector
}

\author{
D A HORNE
}

The present Government has attached considerable importance to the place of the private sector in the provision of health care. The private sector's facilities are seen as part of national health care resources and "The Secretary of State is keen to encourage increased use of them by NHS authorities wherever they can contribute economically and effectively to the care of NHS patients." Authorities have, therefore, been advised to give early consideration to the use of non-NHS facilities. For the first time since the inception of the NHS the private sector is being seen as an acceptable supplement to the Health Service, rather than its alternative and, albeit friendly, competitor.

This paper uses unpublished data from the DHSS and some of the regions to examine the use of contractual arrangements for treating NHS patients in establishments outside the Service. There are several omissions in the available data. Though contractual arrangements have been in use since 1948, data are only available for $1963,1965,1966,1967$, and from 1975 to now. Furthermore, there are differences in reporting the use of contractual arrangements. One authority, for instance, only recently reported the use on a contractual basis of the facilities of a RAF hospital although the arrangement was a long-standing one. This change followed the 1979 Ministry of Defence expenditure review. Such omissions emphasise how little is known of this area of Health Service provision.

\section{Background}

The use of contractual arrangements as a way of providing services and treatment to NHS patients is not new. Since 1948 , when various hospitals were exempted from transfer of ownership to the Ministry of Health, health authorities (at present area health authorities and, after April 1982, district health authorities) have been permitted to arrange for care and treatment to be provided to Health Service patients in facilities outside the NHS. Contractual arrangements with non-NHS institutions are used to help overcome local difficulties in NHS provision or for some forms of treatment that are unavailable in the local NHS. Patients treated under contractual arrangements are admitted by, or with the authority of, the health authority. If it is administratively convenient patients may be referred directly to the contractual institution by the consultant or by general practitioners who have access to general practitioner beds at the institution or even an emergency bed bureau. Such patients remain NHS patients and are not liable for charges: the hospital or nursing home is paid a negotiated amount by the health authority according to the contract.

A contract may be for an "all-in" service that includes medical and surgical treatment as well as supportive services, or for NHS consultants and staff to use the facilities as part of their NHS contracted duties. Contractual arrangements may also be made for general practitioners to admit patients under their care.

School of Humanities and Social Sciences, University of Bath, Bath BA2 7AY

D A HORNE, BA, Social Science Research Council research student
The original intention was that contractual arrangements would be "an interim measure until National Health Service hospitals and specialist services were developed to support entirely the needs of National Health Service patients."” Table I shows the decreasing use of contractual arrangements as a form of Health Service provision during the 1960s. In 1972, as costs for the exempted hospitals rose and incomes fell, a change of Government policy was announced after petitioning by the Association of Independent Hospitals. Health Circular (72) 56 announced that contractual arrangements were to be seen in future as an integral part of providing hospital services. ${ }^{2}$ Health authorities were allowed to consider helping in the financing of a private institution's capital expenditure, but contractual arrangements were not normally to be made with profitmaking hospitals.

By 1981 the DHSS reported that "use of non-NHS facilities on a contractual basis has established itself as a recognised way of providing services. Facilities used in this way have proved an invaluable supplement to local NHS facilities and in many cases the private institution is an integral part of the local NHS."1 Present policy is to encourage the use of contractual arrangements and sees such arrangements "as much part of overall NHS provision as a NHS-run hospital." Arrangements may now be made with profit-making institutions since it is argued that at a time when Health Service facilities are stretched there is nothing but value in the provision of extra resources in the private sector. Table II shows the use of contractual arrangements since the mid-1970s: despite annual fluctuations, the overall trend remains downwards.

\section{Use of contractual arrangements}

The 1979 Royal Commission on the NHS estimated that there were "about 4000 beds in the private sector occupied by NHS patients . . . about $0.8 \%$ of the total beds available to the NHS." 3 From the commission's figures contractual beds accoun-

TABLE I-Use of contractual arrangements in England, 1963-7

\begin{tabular}{cccc}
\hline Year & $\begin{array}{c}\text { Inpatient deaths } \\
\text { and discharges }\end{array}$ & $\begin{array}{c}\text { Outpatient } \\
\text { attendances }\end{array}$ & $\begin{array}{c}\text { New } \\
\text { outpatients }\end{array}$ \\
\hline 1963 & 37376 & 432574 & 67202 \\
1965 & 36569 & 342361 & 67084 \\
1966 & 35447 & 347801 & 62867 \\
1967 & 34527 & 360220 & 63889 \\
\hline
\end{tabular}

TABLE II-Use of contractual arrangements in England, 1975-80

\begin{tabular}{lccc}
\hline & $\begin{array}{c}\text { Inpatient deaths and } \\
\text { discharges and beds } \\
\text { occupied at 31 } \\
\text { December }\end{array}$ & $\begin{array}{c}\text { Outpatient } \\
\text { attendances }\end{array}$ & $\begin{array}{c}\text { New } \\
\text { outpatients }\end{array}$ \\
Year & 28317 & 217031 & 48637 \\
1975 & 29041 & 225991 & 46625 \\
1976 & 26843 & 217696 & 48831 \\
1977 & 26430 & $191560^{*}$ & $49081^{*}$ \\
1978 & 27648 & 175959 & 42900 \\
1980 & 26705 & 116530 & 15857 \\
\hline
\end{tabular}

*Adjusted after an incorrect entry. 
ted for $12 \%$ of the private sector bed stock. Actual numbers though are hard to determine since arrangements with facilities vary and beds may not be continuously occupied by contractual patients. Numbers of patients treated provide a clearer picture and these are shown in tables I and II. The use made of contractual arrangements during recent years has fallen by about $30 \%$ since the 1960s.

\section{REGIONAL USE}

All English regions make at least some use of contractual arrangements, but there are high and low users. The South-west Thames and East Anglia regions are consistently high users of contractual inpatient arrangements, accounting for $19 \%$ and $15 \%$ respectively of the 1980 contractual inpatient case load. In comparison, Trent and Oxford regions are low users, with $2 \%$ and $1 \%$ of the 1980 total. East Anglia and the West Midlands regions make high use of contractual outpatient arrangements while the Northern and South-east Thames regions have none.

There is no clear link between the regional use of contractual arrangements and RHA expenditure (either in total or just for hospital services). As a proportion of RHA expenditure on hospital services, the costs of contractual arrangements are low. In both the South Western and Oxford regions, for example, this was $4 \%$ each (coincidentally) in 1979 . Figures on actual costs are hard to come by but in 1980 the total expenditure on contractual arrangements in England was $£ 22.3 \mathrm{~m}$. In one region, Mersey, the average cost to the RHA per contractual inpatient week was $£ 76.81 \frac{1}{2} \mathrm{p}$ in 1979 . Though it is not a valid basis for comparison, the average inpatient cost per week for the NHS in England was $£ 263.55$ in a "mainly acute" hospital and $£ 166.60$ in a "mainly long-stay" hospital for the financial year 1978-9." As the DHSS and several health authorities have recently pointed out, however, there is little or no indication of how patient treatment costs under contractual arrangements compare with NHS costs. ${ }^{5}$

\section{SPECIALTY USE}

There is a difference according to specialty in the inpatient and outpatient use of contractual arrangements. The largest category of contractual inpatient is the preconvalescent, convalescent, and postoperative patient. In $1980,30 \%$ of contractual inpatients were covered under this category. Surgical patients constituted the second largest group with $16 \%$. Specialties such as maternity, rehabilitation, and diseases of the chest are rarely covered under contractual arrangements. The specialty percentages for inpatient and outpatient contractual attendances are shown in table III.

In contrast with the inpatient distribution, the majority of outpatient attendances are for treatment under the "others" category. Investigations into this category show it to include those specialties not already listed in table III. These cover the range of acute services such as orthopaedics and gynaecology and include accident and emergency treatment. In at least two regions such acute treatment is provided at RAF hospitals and until recently a private hospital in a third region gave its services while the NHS hospital was redeveloped.

\section{Conclusion}

The available information shows the declining use of contractual arrangements as a way of providing services to NHS patients. Nevertheless, they may contribute markedly to health services in several regions.

Any future expansion in the use of contractual arrangements depends less on Government policies than on the private sector demonstrating its cheapness for various forms of patient treatment to otherwise recalcitrant health authorities in the light
TABLE III-Distribution of contractual arrangements by specialty in England in 1980 (1979 figures)

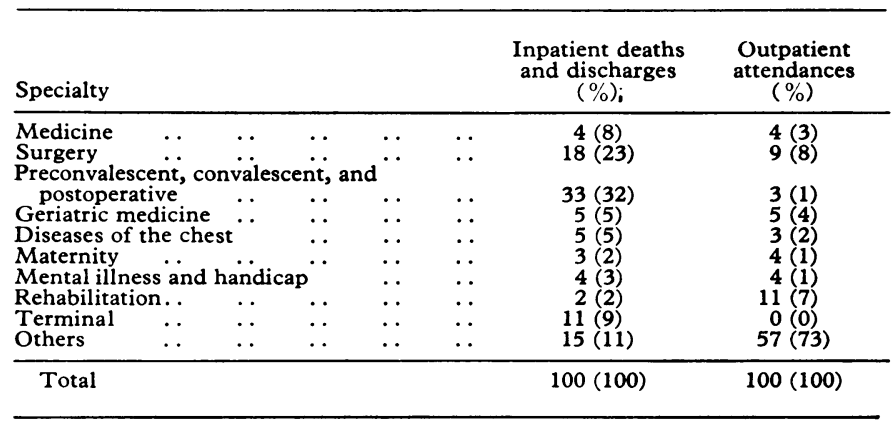

of competing resources. Even so, many NHS authorities may prefer to give priority to developing their own services than enter into contractual arrangements.

\section{References}

${ }^{1}$ Department of Health and Social Security. Contractual arrangements with independent hospitals and nursing homes and other forms of co-operation between the NHS and the independent medical sector. $\mathrm{HC}(81) 1$. London: DHSS, 1981.

${ }^{2}$ Department of Health and Social Security. Contractual arrangements with hospitals and homes outside the National Health Service. HM(72)56. London: DHSS, 1972.

${ }^{3}$ Royal Commission on the National Health Service. Report. Cmnd 7615. London: HMSO, 1979.

4 Department of Health and Social Security. Health Service costing returns, 1979. London: DHSS, 1981.

5 Walker I. The passing-on impasse. The Times Health Supplement 1981 October 10:18.

(Accepted 22 February 1982)

\section{NHS reorganisation}

\section{Community physicians' supplements}

The Joint Negotiating Body for Doctors in Community Medicine and the Community Health Service has agreed that a community physician who undertakes substantial work as a chief officer designate and who continues to carry out the major part of the duties of his existing posts, so that his total work load is greater than normal, should be eligible to receive a supplement of up to $10 \%$ of his current salary (excluding any distinction award). The supplement was payable from 1 January 1982 or from the date of taking up duties as a chief officer designate and ends on 31 March 1982.

\section{Additional allowance for DMT members}

Authorities have already been informed that from 1 January 1982 newly elected clinical members of a "shadow" district management team may be paid an allowance at the same rate ( $£ 1910$ per year) as is paid to clinical members of existing DMTs. In a few cases a doctor may be a member both of the existing DMT or area management team and of its shadow successor. If this means substantial additional work he may receive an additional allowance at the discretion of the "old" authority concerned in consultation with the chairman of the shadow DHA. This allowance will be subject to a maximum of $£ 250$ for the full three-month period from 1 January 1982 to 31 March 1982 and proportionately less for shorter periods. 